\title{
The Chiari/hydrosyringomyelia complex presenting in adults with myelomeningocoele: an indication for early intervention
}

\author{
JJ Craig*,1, WJ Gray ${ }^{2}$ and JP McCann ${ }^{3}$ \\ ${ }^{1}$ Department of Neurology, Royal Victoria Hospital, Belfast, UK; ${ }^{2}$ Department of Neurosurgery, Royal Victoria \\ Hospital, Belfast, UK; ${ }^{3}$ Spinal Injuries Unit, Musgrave Hospital, Belfast, UK
}

\begin{abstract}
Objective: To determine how adults with myelomeningocoele who develop the Chiari/ hydrosyringomyelia complex present, and to determine if surgical intervention influences outcome in these patients.

Methods: A chart review of the 220 patients who attend a clinic for adults with spina bifida and hydrocephalus (CASBAH), and follow-up of the five cases with myelomeningocoele who had surgical intervention for associated symptomatic Chiari/hydrosyringomyelia complex.

Results: Bilateral upper limb weakness and wasting were the commonest presenting symptoms (four patients). Sensory disturbance (three patients) was also common, dysphagia (one) and ataxia (one) occurring less often. The median time to surgical intervention was 36 months. Two patients had a shunting procedure performed in isolation, two foramen magnum decompression in addition to a shunting procedure and one a foramen magnum decompression. Surgical intervention did not completely reverse problems attributed to the Chiari/hydrosyringomyelia complex in any of the cases. One patient died post-operatively. Of the four who survived one had some improvement in function post-operatively, two remained static and one had further mild deterioration.

Conclusion: All adults with myelomeningocoele should be questioned about changes in upper limb function for early detection of Chiari/hydrosyringomyelia complex. Our results suggest that early intervention is needed if further deterioration is to be avoided, and to improve the chances of neurological and functional recovery.
\end{abstract}

Keywords: myelomeningocoele; Chiari; hydrosyringomyelia; adult; presentation; treatment; outcome

\section{Introduction}

The reasons for late neurological deterioration in myelomeningocoele are well documented, ${ }^{1,2}$ and include the development of an associated Chiari malformation with or without hydrosyringomyelia. With the advent of MR scanning it is becoming clearer how common this occurrence is. ${ }^{3,4}$ Most neuroradiological studies however have looked at paediatric and adolescent populations, mirroring clinical studies which have detailed the presenting features and outcome of these patients. ${ }^{5-7}$ Information on how adults with myelomeningocoele who develop the Chiari/hydrosyringomyelia complex present, and how they respond to treatment is in contrast scant, ${ }^{5,8}$ although it is reported, that the outlook in these patients is consistently good with intervention. ${ }^{9}$ The aim of this paper is to review our

*Correspondence: Dr JJ Craig, Department of Neurology, Ward 21, Royal Victoria Hospital, Belfast, BT12 6BA, UK experience of adults with myelomeningocoele, who attend CASBAH, who presented with symptomatic Chiari/hydrosyringomyelia complex for which they had surgical intervention.

\section{Methods}

\section{Patients}

Five patients suitable for study were identified by reviewing the medical records of the 220 adults who attend CASBAH at Musgrave Park Hospital, Belfast. This clinic serves all adult patients ( $>16$ years) with myelomeningocoele in Northern Ireland (population approximately 1.64 million).

A case was defined as a patient with myelomeningocoele who developed symptoms attributable to a Chiari/hydrosyringomyelia complex, confirmed by magnetic resonance imaging, who subsequently had surgical intervention. 


\section{Measures}

All retrospective data was collected by one of the authors (J Craig). Details collected included functional ability before development of the Chiari/hydrosyringomyelia complex, presenting symptoms due to the complex, investigation details, and details of the surgical history. In order to assess outcome the patients were interviewed and examined by one or other of the authors. At this visit, in addition to having a full neurological examination, patients were questioned about their present symptoms and functional abilities, and asked to compare these with their equivalent before surgery.

\section{Results}

\section{Case 1}

A 20-year-old man who had a lumbosacral myelomeningocoele repaired and ventriculoperitoneal shunt inserted at birth presented aged 15 years with slowly progressive weakness and numbness of the hands. On examination he had early bilateral clawing of the fingers, weakness of all small muscles of the hands, dissociated sensory loss to the wrists and hyporeflexia of the arms. There was no evidence of bulbar or cerebellar dysfunction. Prior to the onset of these new symptoms he had been chairbound for 4 years, performed intermittent self-catheterisation and had normal upper limb function, being independent for almost all activities of daily living. From the onset of symptoms however he needed more help with activities of daily living and had lost some key-board skills. MRI showed a Chiari type I abnormality with tonsillar descent to $\mathrm{C} 1$ and a syrinx from $\mathrm{C} 2-\mathrm{C} 7$ (Figure 1). Syringopleural shunting was performed 24 months after the onset of symptoms. At follow-up 48 months after surgery he reported no change in his symptoms from pre-operatively. He had fixed flexion deformities of the fingers. Functional status was unchanged from surgery.

\section{Case 2}

A 31-year-old woman who had a lumbar myelomeningocoele repaired and a ventriculoperitoneal shunt inserted at birth presented aged 24 years with slowly progressive weakness, and numbness of the hands resulting in recurrent burns. On examination she had bilateral weakness of the small muscles of the hands and wrist extensors to MRC grade 4, dissociated sensory loss to the wrists and hyporeflexia of the arms. There was no bulbar or cerebellar dysfunction. Prior to the onset of symptoms she walked with calipers, had no skin breakdown, normal upper limb function and was independent for all daily activities. Nerve conduction study of the upper limbs showed slightly delayed ulnar motor nerve conduction velocities. MRI of the cervical cord showed a Chiari type I abnormality with tonsillar descent to $\mathrm{C} 1$ and a syrinx from $\mathrm{C} 2$ to

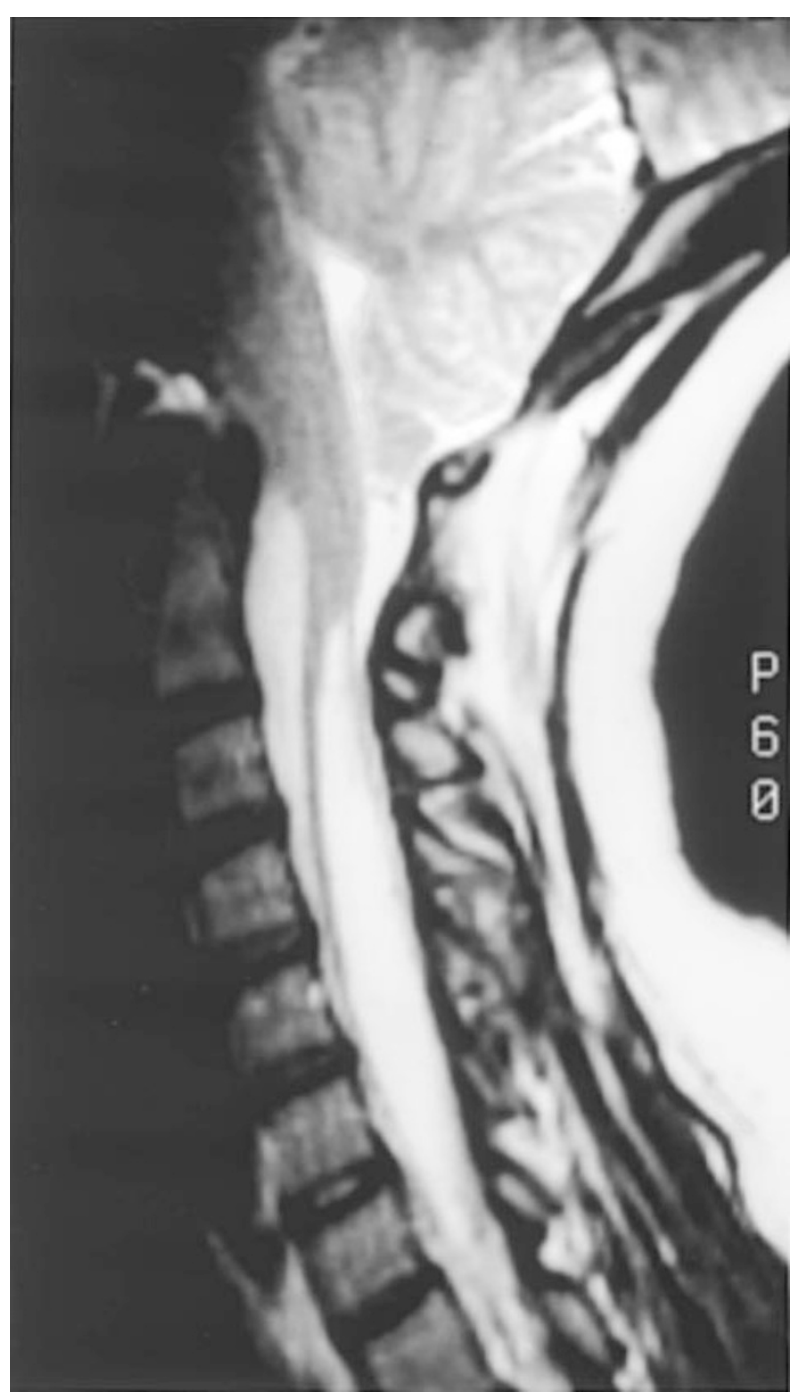

Figure 1 Saggital T2-weighted image of posterior fossa and upper cervical cord demonstrating cerebellar tonsillar descent to $\mathrm{C} 1$ and high signal abnormality situated centrally within the cervical cord extending from $\mathrm{C} 2-\mathrm{C} 7$, with associated cord swelling, consistent with Chiari/hydrosyringomyelia complex (Case 1)

the conus. Syringopleural shunting was performed 36 months after the onset of the symptoms. At follow-up 42 months after surgery she had increased weakness at wrist extension to MRC grade 2 and dissociated sensory loss to below the elbow on the right. A chronic deep ulcer of the right hand developed which required surgical grafting. She needed help with some activities of daily living. MRI 8 months after surgery had shown a significant reduction in the size of the syrinx, especially in the cervical region.

Case 3

A 23-year-old woman who had a lumbar myelomeningocoele repaired at birth presented aged 19 years 
with headaches, pain in the left arm on coughing and progressive arm weakness. On examination she had nystagmus in all directions, wasting of the small muscles of the hand and severe bilateral weakness of finger abductors and finger extensors. She was areflexic but had no sensory loss or bulbar dysfunction. Prior to these symptoms she had been chairbound but was able to transfer independently. She had normal upper limb function and was independent for all activities of daily living, which included intermittent self-catheterization (ISC). She was taking a business administration course which required key-board use. Following the onset of symptoms she required supervision with transfers, and needed help with dressing, feeding and ISC, and was unable to use a key-board. Ulnar motor nerve conduction velocities were slightly slowed bilaterally. MRI of cervical cord showed a Chiari type I abnormality with tonsillar descent to $\mathrm{C} 1$ and a syrinx from $\mathrm{C} 1$ to the conus. CT scan of brain showed longstanding ventriculomegaly. Foramen magnum decompression and insertion of a syringo-pleural shunt was performed 39 months after symptom onset. At followup 18 months after surgery the headaches had settled, and there was some improvement in hand function. MRI showed a marked reduction in the syrinx. Compared with just before surgery she felt there had been an overall improvement in her functional abilities.

\section{Case 4}

A 41-year-old woman who had a sacral myelomeningocoele repaired at birth presented aged 37 years with decreased mobility, incoordination of the left arm and sensory disturbance of the arms. On examination she had marked rotatory nystagmus in all directions, wasting of the small muscles of the hands, ataxia of the left arm and legs and dissociated sensory loss of the arms to the wrists. There was no bulbar dysfunction. Prior to these symptoms she was walking unaided, had normal arm function and was independent for all activities of daily living. After developing symptoms she required some help with activities of daily living. She had a long-standing ulcer of the left foot and underwent a trans-tibial amputation aged 40 years. MRI had showed a Chiari type I abnormality with tonsillar descent to $\mathrm{C} 1$ and a syrinx from $\mathrm{C} 2$ to the conus, with cord expansion of the dorsal region. Foramen magnum decompression was performed 42 months after the onset of symptoms. At follow-up 6 months after surgery there was no change from her pre-operative condition. She was mobilizing with difficulty with crutches and required care for some activities of daily living.

\section{Case 5}

A 29-year-old man who had a lumbar myelomeningocoele repaired and a ventriculoperitoneal shunt inserted at birth presented aged 29 with a 6 week history of headaches, recurrent chest infections, dysphagia, and rapidly progressive upper limb weakness. On examination he was drowsy, dysarthric, had vertical nystagmus on upgaze and decreased palatal movements. He had severe weakness of the left arm especially distally, mild weakness of the right arm and was areflexic. Prior to these symptoms he was chairbound, had no bulbar problems and normal arm function. MRI of the brain and cervical cord showed hydrocephalus with periventricular hypodensity and effacement of the cortical sulci consistent with acutely raised intracranial pressure, Chiari type II abnormality and syringobulbia. He had a ventriculoperitoneal shunt inserted, foramen magnum decompression and a syringopleural shunt inserted. Post-operatively his headaches settled and his arm function almost returned to normal. Despite an improvement in dysphagia he had further chest infections and died of bronchopneumonia 10 weeks after surgery. Ultrasound scan of brainstem prior to death showed collapse of the syringobulbia and CT brain showed resolution of the acute hydrocephalus.

\section{Discussion}

Despite claims that the Chiari malformation with or without associated hydrosyringomyelia always occurs with myelomeningocoele, $, 6,10$ it is becoming apparent with MR imaging that this is not the case. ${ }^{3,4,11}$ Recent studies in paediatric and adolescent populations have shown the incidence of any Chiari malformation or hydrosyringomyelia in patients with myelomeningocoele to be between $57 \%$ to $92 \%$ and $33 \%$ to $57 \%$ respectively, ${ }^{3,4,11}$ with one-quarter of patients becoming symptomatic. ${ }^{4}$ This approximates to the $20 \%$ of children with myelomeningcoele who despite adequate control of hydrocephalus are known to develop signs attributable to the Chiari malformation. ${ }^{6}$ It is unknown however how often these abnormalities occur, or result in symptoms in adults with myelomeningocoele. We have shown five patients attending CASBAH $(2.2 \%)$ who developed functional impairments from an associated Chiari/hydrosyringomyelia complex. How many other patients attending CAS$\mathrm{BAH}$ with asymptomatic Chiari/hydrosyringomyelia complex is unknown, as they have not had MRI. This will be addressed in a further study.

In contrast to paediatric populations where the presentation often suggests lower cranial nerve dysfunction, ${ }^{5,6,9}$ resulting in such symptoms as stridor and difficulty swallowing, our patients presented in a similar way to adults without myelomeningocoele who develop symptoms from the Chiari/hydrosyringomyelia complex. ${ }^{12-15}$ All had upper limb weakness, with or without sensory symptoms and reflex changes, consistent with a central cord syndrome, with fewer having evidence of foramen magnum compression. This might explain the reported difference in mortality between paediatric groups and adults developing this complex. In most adults with myelomeningocoele the greatest threat from developing a symptomatic Chiari/ hydrosyringomyelia complex would instead appear to 
be a decrease in upper limb function; as for children however, the condition can occasionally result in death from lethal bulbar dysfunction, as occurred in one patient in our series.

The benefits of surgery in adults with myelomeningocoele who develop a symptomatic Chiari/hydrosyringomyelia complex are unknown. What evidence there is, is based on a few single or double casereports, ${ }^{5,7,8}$ that do not state how follow-up was performed or measured. Despite our study also consisting of small numbers we have attempted to explicitly present all relevant follow-up details concentrating particularly on functional impairments. Our results suggest that surgical intervention possibly influences the disease process in adults with myelomeningocoele who develop symptoms from the Chiari/ hydrosyringomyelia complex, with only one patient continuing to deteriorate after surgical intervention. It is important to note however that improvement was not full in the other four patients, and that at followup all were significantly more disabled than before the development of symptoms due to the Chiari/hydrosyringomyelia complex. Why this might be different from paediatric studies, in which a few patients have had a complete reversal of their problems from the Chiari/hydrosyringomyelia complex is unknown. ${ }^{5-7,9}$ It might be explained by the long median time (36 months) between symptom onset and surgical intervention in our cases, as paediatric studies have suggested that early intervention results in better outcome. ${ }^{9}$

In conclusion all adults with myelomeningocoele should be asked about their upper limb function at review, and if they report changes in it, investigated as a matter of urgency by MRI with a view to early surgical intervention. For patients with myelomeningocoele struggling to maintain their independence, loss of function from an associated Chiari/hydrosyringomyelia complex is a situation that once recognised should be treated with all due speed to avoid further deterioration and to improve chances of neurological and functional recovery.

\section{References}

1 NC Myrianthopoulus, (ed). Handbook of Clinical Neurology : Malformations, Vol 6 (50). Elsevier Science Publishers BV, 1987.

2 Gilbert JN et al. Central nervous system anomalies associated with myelomeningocoele, hydrocephalus, and the Arnold-Chiari malformation: reappraisal of theories regarding the pathogenesis of poaterior neural tube closure defects. Neurosurg 1986; 18: $559-564$.

3 Kuharik MA, Edwards MK, Grossman CB. Magnetic resonance evaluation of pediatric spinal dysraphism. Pediat Neurosci $1985-$ 1986; 12: $213-218$

4 Azimullah PC, Smit LM, Rietveld-Knol E, Valk J. Malformations of the spinal cord in 53 patients with spina bifida studied by magnetic resonance imaging. Child's Nerv Syst 1991; 7: 63-66.

5 Hoffman HJ, Hendrick BE, Humphreys RP. Manifestations and management of Arnold-Chiari malformation in patients with myelomeningocoele. Child's Brain 1975; 1: $255-259$.

6 Park TS, Hoffman HJ, Hendrick BE, Humphreys RP. Experience with surgical decompression of the Arnold-Chiari malformation in young infants with myelomeningocoele. Neurosurg 1983; 13: $147-152$

7 Park TS, Cail WS, Maggio WM, Mitchell DC. Progressive spasticity and scoliosis in children with myelomeningocoele. Radiological investigation and surgical treatment. J Neurosurg 1985; 62: $367-375$.

8 Arnold AC, Baloh RW, Yee RD, Hepler RS. Internuclear ophthalmoplegia in the Chiari type II malformation. Neurology 1990; 40: $1850-1854$.

9 Bell WO et al. Symptomatic Arnold-Chiari malformation: review of experience with 22 cases. J Neurosurg 1987; 66: 812-816.

10 Urich H. Malformations of the nervous system, perinatal damage and related conditions in early life. In: Blackwood W, Corsellis JAN (eds). Greenfield's Neuropathology, Edward Arnold Ltd: London, 1976, pp 369-377.

11 de Souza MR, Plese JP, Matushita H, Ciquini O. Magnetic resonance imaging in spinal dysraphisms. Arquivos de NeuroPsiquiatria 1994; 52: $243-247$.

12 Levy WJ, Mason L, Hahn JF. Chiari malformation presenting in adults: a surgical experience in 127 cases. Neurosurg 1983; 12: $377-390$

13 Paul KS, Lye RH, Strang AF, Dutton J. Arnold-Chiari malformation: review of 71 cases. J Neurosurg 1983; 58: $183-$ 187.

14 Vaquero J, Martinez R, Arias A. Syringomyelia-Chiari complex: magnetic resonance imaging and clinical evaluation of surgical treatment. J Neurosurg 1990; 73: 64-68.

15 Pillay PK, Awad IA, Little JR, Hahn JF. Symptomatic Chiari malformation in adults: A new classification based on magnetic resonance imaging with clinical and prognostic significance. Neurosurg 1991; 28: 639-645. 